\title{
Modally conditioned mood-switch: The case of ADVISE-Predicates in Greek*
}

\author{
Despina Oikonomou \\ Humboldt University of Berlin
}

\begin{abstract}
This paper discusses a case of mood-switch with predicates expressing advice, exhortation, request (hence, ADVISE-Ps). While, in most studies, these predicates are typically categorized as combining with subjunctive mood, I show that they can combine with indicative if they embed a prioritizing modal operator. This type of switch provides further evidence for the mood-as-modal approach, under which indicative expresses simple necessity whereas subjunctive encodes human necessity as recently argued by Portner \& Rubinstein (2020). Building on a meaningful approach to mood, I argue that this special type of modally conditioned mood-switch is associated with the bieventive character of ADVISE-Ps, which can be decomposed into a cause speech event and a prioritizing (PRT-)state (Martin \& Schäfer 2013; Grano 2018). In this way, ADVISE-Ps can combine either with subjunctive licensed by the embedding PRT-state or with indicative and a prioritizing modal operator licensed by the communication cause event and the PRT-state accordingly.
\end{abstract}

Keywords: Subjunctive/indicative mood, mood-switch, prioritizing modality, event relativity, bieventive predicates

\section{Introduction: The ADVISE-puzzle}

Mood distribution in Balkan and Romance languages has received extensive attention (Farkas 1992, 2003; Giorgi \& Pianesi 1997; Quer 2001, 2009; Schlenker 2005; Giannakidou 1998, 2015; Portner 1997; Portner \& Rubinstein 2012; Portner 2018; Portner \& Rubinstein 2020; Mari \& Portner 2018; Silk 2018; Villalta 2008). While some clear-cut patterns have been noticed there is also recurring evidence for cross- and intra-linguistic mood variability (Farkas 1992; Portner 2018; Portner

* I would like to thank Kai von Fintel, Magdalena Kaufmann, Fabienne Martin and Vina Tsakali for their valuable feedback. Also many thanks to Carmen Dobrovie Sorin and the audience at the University of Bucharest, the audience and the reviewers of BCGL13, the audience at the Athens Semantics Group, and of course the SALT31 reviewers and audience. All errors are, of course, mine. This work is funded by AL 554/8-1 (DFG Gottfried Wilhelm Leibniz Preis 2014 to Artemis Alexiadou). 
\& Rubinstein 2020; Giannakidou \& Mari 2021). This paper brings forth a case of variability with prioritizing predicates of communication in Greek.

Predicates like simvulevo 'advise', ipohreono 'require', diatazo 'order', protrepo 'urge', (hence ADVISE-Ps) which have been analyzed as subjunctive-selecting, can combine with indicative as long as they embed a prioritizing modal operator. The examples in (1) illustrate the relevant minimal contrasts with the verb simvulevo 'advise'. (1a) exhibits the typical pattern in which ADVISE is followed by the subjunctive particle na. (1b) is our critical example: ADVISE is followed by the indicative complementizer oti 'that' embedding a prioritizing modal operator prepi 'should'. 1 (1a) and (1b) are judged to be equally acceptable by native speakers of Greek. As we show in Appendix A, acceptability judgements for the marked ADVISE+IND+MOD sequence may vary depending on the predicate and the way the sentence is constructed. Based on the data so far, we can conclude that a number of predicates exhibit the mood-switch pattern in (1) at least for a subset of speakers. Crucially, (1c), in which ADVISE combines with the indicative complementizer oti without embedding a PRT-modal is unacceptable for all speakers. Similarly, (1d) which takes a subjunctive complement embedding a PRT-modal is also ungrammatical.

(1) a. Kapji simvulepsan ton Bernie na paretithi. some.PL advise.3PL the Bernie SUBJ resign.3SG 'Some advised Bernie to resign.'

b. Kapji simvulepsan ton Bernie oti prepi na paretithi. some.PL advise.3PL the Bernie that ${ }_{\text {ind }}$ should NA resign.3SG 'Some advised Bernie that he should resign.'

c. *Kapji simvulepsan ton Bernie oti (tha) paretithi. some.PL advise.3PL the Bernie that ${ }_{\text {ind }}$ FUT resign.3SG Intended: 'Some advised Bernie that he should/better resign.'

d. *Kapji simvulepsan ton Bernie na prepi na paretithi. some.PL advise.3PL the Bernie SUBJ should NA resign. $3 \mathrm{SG}$ Intended: 'Some advised Bernie that he should/better resign.'

Importantly, this type of switch is only licensed with PRT-P(redicates)s of communication. Non-communication PRT-Ps cannot combine with indicative even if

1 The second na-particle after the modal prepi 'should' is glossed as NA in order to avoid confusion with the higher $n a$ which introduces the subjunctive clause in (1a). It is not clear if this embedded NA has the same status as the higher SUBJ-na. If we treat this as a modal operator then we need an analysis of modal concord which allows the second occurrence of na to not be interpreted under the modal prepi. What is important for the purposes of this paper is that this embedded na is not associated with the matrix predicate. Its presence is due to the embedded modal prepi and thus the type of the matrix predicate is irrelevant for its licensing. 
there is an embedded PRT-modal. In (2a), thelo 'want' takes a subjunctive proposition. When WANT combines with the indicative complementizer $\left(\mathrm{C}_{\mathrm{IND}}\right)$ as in $(2 \mathrm{~b})$, the sentence is ungrammatical and the embedded modal operator cannot rescue it. Predicates like skopevo 'intend', efhome 'wish', protimo 'prefer' exhibit the same restriction.

(2) a. Thelun na pane stin Elada. want.3PL SUBJ go.3PL to-the Greece.

'They want that they should go to Greece.'

b. *Thelun oti prepi na pane stin Elada. Plan.3PL that ${ }_{\text {ind }}$ should NA go.3PL to-the Greece.

Intended: 'They want that they should go to Greece.'

This set of examples leads us to the following generalizations:

i. PrT-Ps typically combine with subjunctive mood (SUBJ).

ii. Communication PRT-Ps also combine with indicative (IND) if they embed a PRT-modal.

iii. Non-communication PRT-Ps cannot combine with IND.

I argue that the mood-switch attested with communication PRT-Ps can be explained on the basis of two independent theoretical assumptions: i) MOOD functions as a modal operator (mood-as-modal approach, pace Kratzer 2016; Portner \& Rubinstein 2020) and ii) communication PRT-Ps comprise of two subevents (a communication cause event and a PRT-state), which can provide the modal background for two distinct modal operators, i.e. the $\mathrm{C}_{\mathrm{IND}}$ and the PRT-modal. The account builds on the analysis of attitude-Ps as predicates of situations (decompositional analysis of attitudes, Portner 1997, Kratzer 2006, 2016, Moulton 2009a, Grano 2018, Portner \& Rubinstein 2020). SUBJ can be replaced by IND+PRT-modal due to the bieventive character of ADVISE-Ps. Under Hacquard's (2006) event relativity of modals, I show that ADVISE-Ps, being bieventive, can determine the modal flavor of two distinct operators (i.e. the emdedded PRT-modal and the IND-operator in (1b)). This is not possible with monoeventive PRT-Ps like WANT, DESIRE, PLAN (2b) which can only determine the flavor of a single modal.

The following section distinguishes two lines of analysis in explaining mood distribution; the selectional and the meaningful approaches to mood. Building on a meaningful approach to mood, Section 3 accounts for the puzzle of mood-switch with ADVISE-PS and explains the illicit patterns with other types of predicates. Section 4 briefly introduces communication-Ps which can take either SUBJ or IND with a clear difference in the derived modal flavor. Section 5 discusses certain implications for the mood-as-modal approach and addresses some open questions. 
Modally conditioned mood-switch

\section{Mood-as-modal approach}

In this section I present the basic assumptions about the semantic contribution of mood building on Portner 2018; Portner \& Rubinstein 2020. First I introduce some basic background on selectional approaches to mood and then I discuss the mood-as-modal approach.

\subsection{Selectional approaches to mood}

The general schema of selectional approaches to mood distribution can be given as in (3). Depending on the approach, IND or SUBJ can be the default/elsewhere case. The distribution of the default/elsewhere mood is determined on the basis of $\neg y$ or $\neg x$ accordingly (see Portner 2018 for a comprehensive review of the theories).

(3) Mood distribution

a. Mood $\rightarrow$ IND / _ Semantic environment with property $x$

b. Mood $\rightarrow$ SUBJ / _ Semantic environment with property $y$

An example of an approach in which the indicative is the marked case is the Veridicality approach which suggests that indicative is lisenced when the embedding predicate is subjectively or objectively veridical, i.e. the attitude holder commits to the truth of the embedded proposition (Giannakidou 1998, 2015; Giannakidou \& Mari 2021 but see also Farkas 1992, 2003; Quer 2001; Schlenker 2005 a.o.). An example which takes the subjunctive to be the marked case, is the Orderingsemantics approach which suggests that the ordering/comparative semantics of a predicate license SUBJ. Under this view, the default/ elsewhere-mood is IND. (Giorgi \& Pianesi 1997; Villalta 2008 a.o.).

The ordering semantics served as the starting point for the meaningful approach to mood that we consider below. However, under the general selectional schema in (3), either type of anaysis predicts that communication PRT-Ps like ADVISE, URGE, RECOMMEND, commonly labelled directives, select for SUBJ (see e.g. Giannakidou 2015; Giannakidou \& Mari 2021; Villalta 2008). The fact that communication PRT-Ps can combine with IND+MOD without any apparent meaning shift (it remains nonveridical and has ordering semantics, when combining with IND + MOD) presents a challenge for both types of analysis. In what follows, I argue that this type of mood-switch can be explained if we follow a meaningful approach to mood as a modal operator (Kratzer 2016; Portner \& Rubinstein 2020).

\subsection{Towards assigning a modal meaning to mood-operators}

Selectional approaches to mood explained a number of cross-linguistic patterns and settled the ground for subtler distinctions intra- and cross-linguistically. At the 
same time, converging evidence from different directions supported the hypothesis that attitude-Ps are predicates of situations and that the attitude/modal semantics is contributed by some component in the embedded proposition (Portner 1997, Kratzer 2006, Moulton 2009a, Grano 2018; Demirok, Özyıldız \& Öztürk 2019, Portner \& Rubinstein 2020). The locus of modality has been attributed to i) complementizers (Kratzer 2006; Moulton 2009b; Elliott 2020; Demirok et al. 2019; Driemel \& Kouneli 2020) ${ }^{2}$, ii) to-infinitives (Portner 1997; Bhatt 2008; Hackl \& Nissenbaum 2012; Grano 2018), iii) the English inherent subjunctive (Safir 2020) and iv) the IND/SUBJ-mood (Kratzer 2016; Portner \& Rubinstein 2020).

Building on Portner \& Rubinstein's (2020) approach, I argue that SUBJ and IND are modal operators. Specifically, I adopt from P\&R's analysis, the idea that IND expresses simple necessity with a single background (i.e. only a modal base) while SUBJ encodes human necessity so that the worlds compatible with the modal base (i.e. doxastic) are ranked with respect to an ordering source (i.e. prioritizing) requiring that the best-ranked belief worlds be ones in which p is true (Portner \& Rubinstein 2020). Unlike P\&R, I do not assume that mood-operators introduce a thematic relation between the matrix predicate and the embedded proposition. I follow Kratzer (2016), who treats mood as modal operator with its modal base and ordering source being relativized to the matrix event via binding (Hacquard 2006,2010 ) as shown in (4). Although we could model the meaning of mood in a different way, it is crucial for the analysis in the next section that we allow $\mathrm{C}_{\mathrm{IND}}$ to be relativized to a higher event which does not take the proposition as its complement. For this reason, we stick to Hacquard's (2006) analysis, which offers the possibility to achieve a dependency relation between $\mathrm{C}_{\mathrm{IND}}$ and a matrix operator without being in a strictly local relation. In the case of Greek, I take the indicative complementizer $o t i$ 'that' to function as the indicative operator encoding simple necessity as in (4a). Similarly I take the subjunctive particle $n a$ to function as the subjunctive operator expressing human necessity as shown in $(4 \mathrm{~b})^{3}$.

2 The idea that complementizers contribute to the interpretation has been implemented in different ways with important differences among the cited works. In this paper, SUBJ and IND are treated as modal operators following Kratzer (2016); Portner \& Rubinstein (2020). Treating SUBJ and IND as modal operators allows us to derive a link between the higher communication cause event and $\mathrm{C}_{\mathrm{IND}}$. However, the data in this paper are not to be taken as evidence against different analyses of $\mathrm{C}$ as identifying the content of the matrix predicate in other environments. As suggested in various works recently, complementation strategies can vary between different constructions and languages (Moulton 2009b; Demirok et al. 2019; Bondarenko 2020 a.o.).

3 The fact that Greek has an indicative complementizer and a distinct SUBJ particle allows us to treat them as the exponent of the mood operator. Notice that I do not take a stance regarding the syntax of the SUBJ particle, and I focus more on its semantic contribution. For a discussion about the syntax of SUBJ-particles and their relation with indicative complementizers see Roussou 2010 and Dobrovie-Sorin 2001. 
Modally conditioned mood-switch

$$
\begin{aligned}
& \text { (4) a. }[[\mathrm{IND}]]=\lambda f_{\langle\varepsilon, s t t\rangle} \lambda e \lambda q_{\langle s t\rangle} \lambda w . \forall w^{\prime \prime} \in \cap f(e, w) \rightarrow q\left(w^{\prime \prime}\right) \\
& \text { b. }[[\mathrm{SUBJ}]]=\lambda f_{\langle\varepsilon, s t t\rangle} \lambda g_{\langle\varepsilon, s t\rangle} \lambda e \lambda q_{\langle s t\rangle} \lambda w . \forall w^{\prime} \in \operatorname{Best}_{(f, g, e, w)} \rightarrow q\left(w^{\prime}\right)
\end{aligned}
$$

The motivation for a meaningful approach to mood comes from different angles. First, as mentioned above, different phenomena point to the direction of locating the modal component at the embedded proposition (Kratzer 2006; Moulton 2009b and subsequent work). Second, selectional approaches to mood face challenges which seem to be addressed in a more satisfactory way under a meaningful approach to mood. Portner \& Rubinstein (2020) analyse variable mood selection with the predicate HOPE in French and Spanish. Although HOPE has the same meaning in the two languages, in Spanish it requires SUBJ whereas in French the preference is for IND. P\&R argue that a mood-as-modal approach can better explain mood flexibility by introducing a unification mechanism of modal backgrounds. Giannakidou (2015), argues that in subjunctive epistemic questions, SUBJ functions as a possibility modal. In Oikonomou 2016, following a covert modal approach to directives (pace Kaufmann 2012), I argued that in matrix subjunctives there is a covert PRT-modal operator. Stegovec (2019) provided a modal analysis for the Slovenian subjunctive. Thus, in view of the decompositional approach to attitude verbs, the hypothesis that mood functions as a modal in all environments comes as a natural conclusion. In this direction, we can also account for the current mood-switch puzzle.

\section{Embedding under ADVISE-PS: The possibility for bieventive anchoring}

Now that we have introduced an analysis of MOOD as a modal relativized to events (4), the missing piece to understand mood flexibility with ADVISE-PS is the semantics of ADVISE-PS and the way they can combine with the embedded clause.

\subsection{On the semantics of ADVISE-PS}

Under a decompositional view to attitude verbs, attitude-Ps are treated as predicates of situations with content which can determine the flavor of an embedded modal based on the event relativity approach. However, ADVISE-Ps are more complex. Martin \& Schäfer (2013), Grano (2018) have shown that certain communication attitude-Ps are bieventive, i.e. they are decomposed into a causing event and an attitude state. Grano (2018) suggests that a predicate like persuade roughly means cause to have a rational state. The causing event has communicative content.

A similar decomposition analysis can be implemented for ADVISE-Ps with a critical difference: When $x$ advises $y, x$ does not necessarily cause $y$ to have a PRT-state. $x$ intends to cause $y$ to have a PRT-state but $x$ might fail, as shown in (5).

(5) I advised John to leave but he didn't listen to me. He wanted to stay. 
In order to capture this intend-to-cause meaning, I follow Martin \& Schäfer (2013), who introduce the term defeasible causatives for verbs like encourage, flatter, provoke, predict, exhort, urge, warn. Defeasible causatives denote "an act performed with the intention of triggering a certain result" (Martin \& Schäfer 2013: 2). Martin \& Schäfer (2013) following Koenig \& Davis (2001), analyse these predicates as bieventive involving a sublexical modality component.

Drawing on Martin \& Schäfer's (2013) analysis, I analyse ADVISE as a bieventive predicate comprising from a communication (report) event towards an Addressee (Ad-ee) $x$ which, when it is successful (i.e. in all worlds in which its goal is achieved), causes $x$ to be in a certain prioritizing state. ${ }^{4}$ In the entry in (6), I use the term Report to express the communication event. This follows Portner \& Rubinstein's (2020) characterization of verbs like say, as providing a Reported Common Ground content. ${ }^{5}$ The external argument, the agent of the report event, is introduced by a higher Voice head.

(6) $\left[\left[\operatorname{Report}_{\text {Cause }}\right]\right]=\lambda p_{\langle\varepsilon, s t\rangle} \lambda x_{e} \cdot \lambda e_{\varepsilon} \cdot \lambda w_{s} \cdot \operatorname{Report}(\mathrm{e}, \mathrm{w}) \wedge A d-e e(e, w)=x \wedge$ $\left[\forall w_{\text {suc }}\right.$. The goal of Report $(e, w)$ is achieved in $w_{\text {suc }} \rightarrow \exists e_{1} \cdot \operatorname{Cause}\left(\mathrm{e}_{1}, w_{\text {suc }}\right)$ $\left.=e \wedge \mathrm{p}\left(\mathrm{e}_{1}, w_{\text {suc }}\right)\right]$

The attitude subevent expresses a prioritizing state (PRT) with PRT-content. It denotes a function taking as its argument a proposition and an individual and returns a function from events to propositions. Crucially, the experiencer argument is in a control relation (i.e. obligatorily bound) with the addresse argument of the Report $_{\text {Cause }}$ event. The priority PRT-worlds are presented as $w^{\odot}$.

$$
\left[\left[\mathrm{v}_{\mathrm{PRT}}\right]\right]=\lambda q_{\langle s t\rangle} \lambda x_{e} \lambda e_{\varepsilon} \lambda w_{s}^{\odot} \cdot \operatorname{PRT}\left(e, w^{\odot}\right) \wedge \operatorname{EXP}\left(e, w^{\odot}\right)=x \wedge q\left(w^{\odot}\right)
$$

Now that we have a meaning for ADVISE-Ps and mood, we show how the two distinct patterns, i) ADVISE+SUBJ and ii) ADVISE+IND+PRT-modal, can be derived.

\subsection{ADVISE-Ps + SUBJ}

Given the prioritizing content of $v_{\mathrm{PRT}}$, under any mood theory, we predict that it combines with SUBJ-mood. Under the present analysis, the SUBJ-operator determines its modal content via anchoring to the PRT-state à la Hacquard 2006, 2010.

4 This means that the PRT-state needs to be in the scope of the teleological modal, such that in all worlds in which the goal of the cause- $e$ is achieved, there is a PRT-state for $x$. I am grateful to Magdalena Kaufmann for discussion on this. Events and states are treated as eventualities $e$, of type $\varepsilon$.

5 As Magdalena Kaufmann (p.c.) points out the contribution of reported common ground (rpg) is not entirely clear with ADVISE-Ps. Portner \& Rubinstein (2020) describe rpg for a saying event $e$, as the common ground shared by the reported interlocutors just before e, plus what was proposed for addition to this background in $e$. In the absence of a better characterization for the content of the communication event in ADVISE-Ps, I stick to rpg leaving subtler content definition for future work. 
Modally conditioned mood-switch

The modal base and the ordering source of SUBJ is relativized to the PRT-state via event binding, represented as $\beta$-binding. After this point, the derivation is typical for

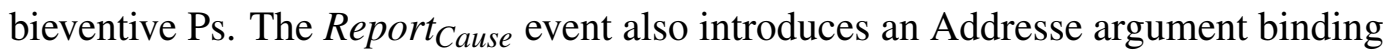
the Experiencer of the PRT-state but it is omitted in the derivation for space reasons.

(8) Derivation for (1a):

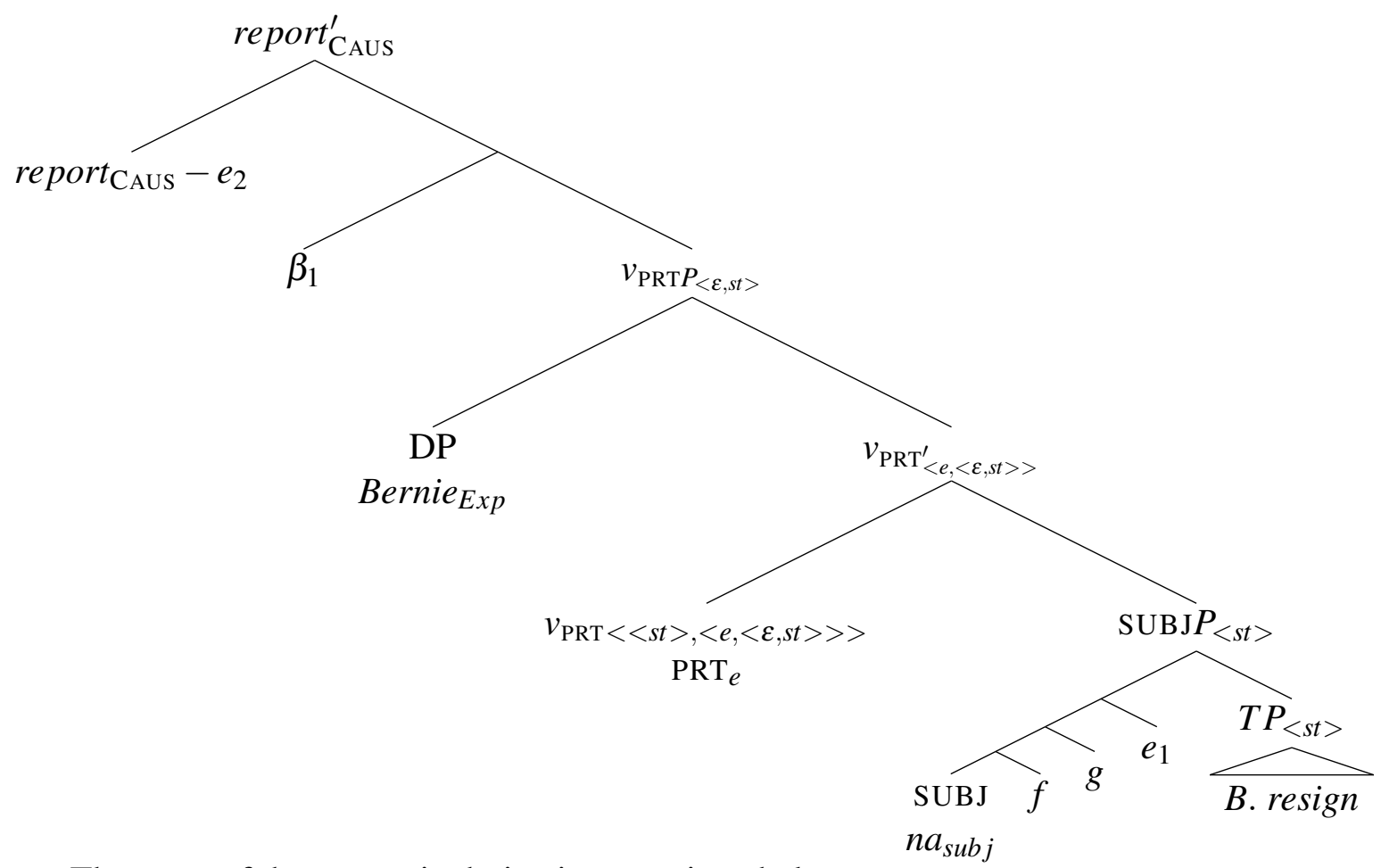

The steps of the semantic derivation are given below:

(9) a. $[[\mathrm{TP}]]=\lambda w$. B.resign $(w)$

b. $[[\mathrm{SUBJP}]]=\lambda w \cdot \forall w^{\prime} \in \operatorname{Best}_{\left(f, g, e_{1}, w\right)} \rightarrow \operatorname{B} \cdot \operatorname{resign}\left(\mathrm{w}^{\prime}\right)$

c. $\left[\left[\mathrm{v}_{\mathrm{PRT}^{\prime}}\right]\right]=\lambda x \lambda e \lambda w^{\odot} \cdot \operatorname{PRT}\left(\mathrm{e}, \mathrm{w}^{\ominus}\right) \wedge \operatorname{EXP}\left(e, w^{\odot}\right)=x \wedge$ $\forall w^{\prime} \in \operatorname{Best}_{\left(f, g, e_{1}, w^{\ominus}\right)} \rightarrow$ B.resign $\left(w^{\prime}\right)$

d. $\left[\left[\mathrm{v}_{\mathrm{PRTP}}\right]\right]=\lambda e \lambda w^{\odot} \cdot \operatorname{PRT}\left(\mathrm{e}, \mathrm{w}^{\odot}\right) \wedge \operatorname{EXP}\left(e, w^{\odot}\right)=$ Bernie $\wedge$ $\forall w^{\prime} \in \operatorname{Best}_{\left(f, g, e_{1}, w^{\odot}\right)} \rightarrow$ B.resign $\left(w^{\prime}\right)$

e. $\left[\left[\beta_{1} \mathrm{~V}_{\mathrm{PRTP}}\right]\right]=\lambda e_{1} \lambda w^{\odot} \cdot \operatorname{PRT}\left(\mathrm{e}_{1}, w^{\odot}\right) \wedge \operatorname{EXP}\left(e_{1}, w^{\odot}\right)=$ Bernie $\wedge$ $\forall w^{\prime} \in \operatorname{Best}_{\left(f, g, e_{1}, w^{\diamond}\right)} \rightarrow$ B.resign $\left(w^{\prime}\right)$

f. $\left[\left[\operatorname{Report}_{\text {Cause }}^{\prime}\right]\right]=\lambda x_{e} \cdot \lambda e_{\varepsilon} \cdot \lambda w_{s} \cdot \operatorname{Report}(\mathrm{e}, \mathrm{w}) \wedge A d-e e(e, w)=x \wedge\left[\forall w_{\text {suc }}\right.$. the goal of $\operatorname{Report}(e, w)$ is achieved in $w_{\text {suc }} \rightarrow \exists e_{1}$. Cause $\left(\mathrm{e}_{1}, w_{\text {suc }}\right)=e$ 


$$
\begin{aligned}
& \wedge\left[\operatorname{PRT}\left(e_{1}, w_{\text {suc }}\right) \wedge \operatorname{EXP}\left(e_{1}, w_{\text {suc }}\right)=\text { Bernie } \wedge\right. \\
& \left.\left.\forall w^{\prime} \in \operatorname{Best}_{\left(f, g, e_{1}, w_{\text {suc }}\right)} \rightarrow \text { B.resign }\left(w^{\prime}\right)\right]\right] \\
& \text { g. }\left[\left[\operatorname{Report}_{\text {Cause }} P\right]\right]=\lambda e_{\varepsilon} \cdot \lambda w_{s} \cdot \operatorname{Report}(\mathrm{e}, \mathrm{w}) \wedge A d-e e(e, w)=\text { Bernie } \wedge \\
& {\left[\forall w_{\text {suc }} \text {. the goal of Report }(e, w) \text { is achieved in } w_{\text {suc }} \rightarrow \exists e_{1} \text {.Cause }\left(\mathrm{e}_{1}, w_{\text {suc }}\right)\right.} \\
& =e \wedge\left[\operatorname{PRT}\left(e_{1}, w_{\text {suc }}\right) \wedge \operatorname{EXP}\left(e_{1}, w_{\text {suc }}\right)=\text { Bernie } \wedge\right. \\
& \left.\left.\forall w^{\prime} \in \operatorname{Best}_{\left(f, g, e_{1}, w_{\text {suc }}\right)} \rightarrow \text { B.resign }\left(w^{\prime}\right)\right]\right] \\
& \text { h. }\left[\left[\beta_{2} \operatorname{Report}_{\text {Cause }} P\right]\right]=\lambda e_{2} \cdot \lambda w_{s} \text {. Report }\left(\mathrm{e}_{2}, w\right) \wedge A d-e e\left(e_{2}, w\right)=\text { Bernie } \\
& \wedge\left[\forall w_{\text {suc }} \text {. the goal of Report }\left(e_{2}, w\right) \text { is achieved in } w_{\text {suc }} \rightarrow \exists e_{1} \text {.Cause }\left(\mathrm{e}_{1}, w_{\text {suc }}\right)\right. \\
& =e_{2} \wedge\left[\operatorname{PRT}\left(e_{1}, w_{\text {suc }}\right) \wedge \operatorname{EXP}\left(e_{1}, w_{\text {suc }}\right)=\text { Bernie } \wedge\right. \\
& \left.\left.\forall w^{\prime} \in \operatorname{Best}_{\left(f, g, e_{1}, w_{\text {suc }}\right)} \rightarrow \operatorname{B.resign}\left(w^{\prime}\right)\right]\right]
\end{aligned}
$$

Once the higher event variable is bound, the interpretation we get is that there is a REPORT-event $e_{2}$ towards Bernie which, in every world $w_{\text {suc }}$ in which the goal of $e_{2}$ is achieved, $e_{2}$ triggers a PRT-state $e_{1}$ in which the Experiencer is Bernie and in the best-worlds $w^{\prime}$ given the priorities of Bernie in $e_{1}, w_{\text {suc }}$, Bernie resigns in $w^{\prime}$.

Two issues deserve our attention here. ${ }^{6}$ First, an advising event is considered successful (i.e. its goal is achieved) not just if Ad-ee $x$ acquires the intended PRT-state but also if $x$ acts in accordance with this PRT-state. To account for this observation, I build on Condoravdi \& Lauer 2012, postulating that if somebody is publicly committed to a PRT-state, they are also publicly committed to act as if they have this PRT-state. For example, in (10B) we understand that the advisee adopts the suggested PRT-state and thus is committed to act accordingly. If he shares the PRT-state but he knows that he cannot fulfil the prejacent, he has to express this as in $\left(10 \mathrm{~B}^{\prime}\right)$.

A: I advise you to leave tomorrow.

$\mathrm{B}: \mathrm{OK}$ !

$\mathrm{B}^{\prime}$ : This would be ideal but there is no train or bus tomorrow.

Alternatively, we could say that ADVISE-Ps are only felicitous if at the time of the advising event there was a decision problem for which the prejacent of ADVISE presents an optimal solution (see Kaufmann's practical context). This needs to be further elaborated in the future.

The second point is that the person who offers advice, already favors (or at least doesn't object) the prejacent. This is parallel to the notion of speaker endorsement in imperatives (Schwager 2006; Kaufmann 2012). The semantics in (9h) do not provide any information about the PRT-state of the advisor. A tentative suggestion is that when somebody publicly attempts to cause a PRT-state for $\phi$, then they are also publicly committed to have a priority for $\phi$. For instance, if somebody advises their friend to leave but they act as to prevent this, they are unreliable advisors.

$6 \mathrm{I}$ am grateful to Omri Amiraz for bringing up these issues during the presentation at SALT and to Magdalena Kaufmann for further discussion. 
Modally conditioned mood-switch

\subsection{ADVISE-PS + IND + PRT-MODAL}

Having shown the derivation for the default pattern in which ADVISE combines with SUBJ, I now turn to our critical example in (11), repeated from (1b), in which ADVISE combines with $\mathrm{C}_{\mathrm{IND}}$ oti embedding a modal operator.

(11) Kapji simvulepsan ton Bernie oti prepi na paretithi. some.PL advise.3PL the Bernie that ${ }_{\text {ind }}$ should NA resign.3SG

'Some advised Bernie that he should resign.'

As mentioned above, in this case the embedded modal prepi is obligatory (see also Appendix A). I take this modal, which expresses human necessity, to be high enough, in a way that its modal base and ordering source are relativized to the matrix PRT-state and not to the circumstances of the local event. $\mathrm{C}_{\mathrm{IND}}$ expresses simple necessity with a modal base anchored to the matrix report ${ }_{\mathrm{CAUS}}$ event.

(12) Derivation for $(1 \mathrm{~b} / 11)$

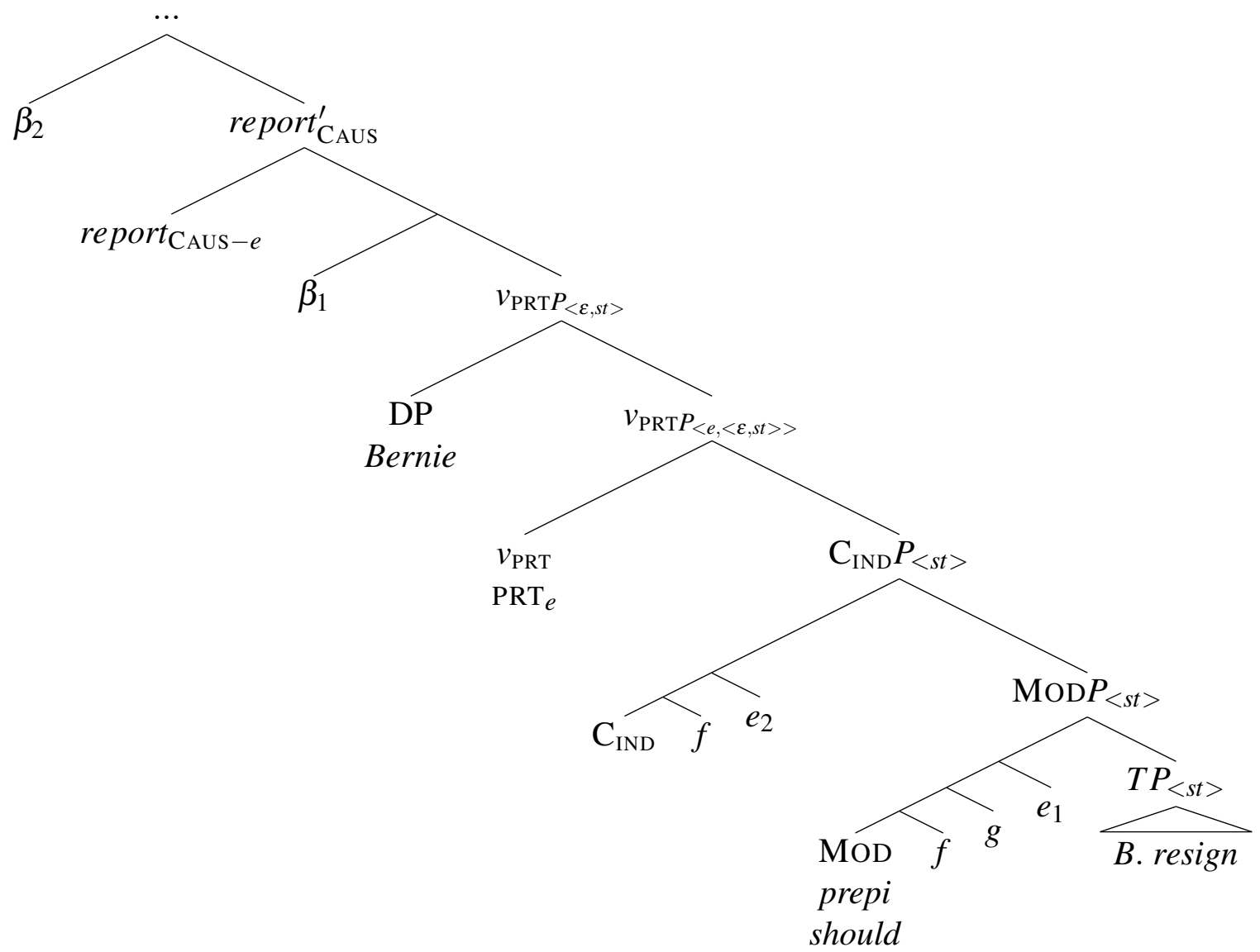


At the level of ModP we get a modalized proposition with the modal base and the ordering source being relativized to $e_{1}$. This proposition is the complement of the modal $\mathrm{C}_{\text {IND }}$. In this way the PRT is evaluated in worlds which are consistent with the reported common ground in $e_{2}$. In turn, the doubly modalized proposition becomes the argument of $v_{\mathrm{PRT}}$. Once the report CAUS $_{\text {Aus }}$ event is interpreted we derive the interpretation that there is a REPORT-event $e_{2}$ towards Bernie which, in every world $w_{\text {suc }}$ in which the goal of $e_{2}$ is achieved, e $e_{2}$ triggers a PRT-state $e_{1}$ in which the Experiencer is Bernie and all worlds w" consistent with the reported CG in $e_{2}, w_{\text {suc }}$, are worlds in which all worlds consistent with the priorities of Bernie in $e_{1}, w_{\text {suc }}$, are worlds in which Bernie resigns. Therefore, the more marked construction has an additional modal component relativized to the reported $C G$ of the cause event.

$$
\begin{aligned}
& \text { a. }[[\operatorname{MoDP}]]=\lambda w \cdot \forall w^{\prime} \in \operatorname{Best}_{\left.f, g, e_{1}, w\right)} \rightarrow \operatorname{Bresign}\left(w^{\prime}\right) \\
& \text { b. }\left[\left[\mathrm{C}_{\mathrm{INDP}}\right]\right]=\lambda w . \forall w^{\prime \prime} \in \cap f\left(e_{2}, w\right) \rightarrow\left[\forall w^{\prime} \in \operatorname{Best}_{\left(f, g, e_{1}, w^{\prime \prime}\right)} \rightarrow \operatorname{Brresign}\left(w^{\prime}\right)\right] \\
& \text { c. }\left[\left[\mathrm{v}_{\mathrm{PRT}}^{\prime}\right]\right]=\lambda x \lambda e \lambda w^{\odot} \cdot \operatorname{PRT}^{\prime}\left(e, w^{\odot}\right) \wedge \operatorname{EXP}\left(e, w^{\odot}\right)=x \wedge\left[\forall w^{\prime \prime} \in \cap f\left(e_{2}, w^{\odot}\right)\right. \\
& \left.\rightarrow\left[\forall w^{\prime} \in \operatorname{Best}_{\left(f, g, e_{1}, w^{\prime \prime}\right)} \rightarrow \text { B.resign }\left(w^{\prime}\right)\right]\right] \\
& \text { d. }\left[\left[\beta_{1} \mathrm{~V}_{\mathrm{PRT}} P\right]\right]=\lambda e_{1} \lambda w^{\odot} \text {. PRT' }\left(e_{1}, w^{\odot}\right) \wedge \operatorname{EXP}\left(e_{1}, w^{\odot}\right)=\text { Bernie } \wedge\left[\forall w^{\prime \prime}\right. \\
& \left.\in \cap f\left(e_{2}, w^{\odot}\right) \rightarrow\left[\forall w^{\prime} \in \operatorname{Best}_{\left(f, g, e_{1}, w^{\prime \prime}\right)} \rightarrow \operatorname{B.resign}\left(w^{\prime}\right)\right]\right] \\
& \text { e. }\left[\left[\operatorname{report}_{\mathrm{CAUS}}^{\prime}\right]\right]=\lambda x_{e} \cdot \lambda e_{\varepsilon} \cdot \lambda w_{s} \cdot \operatorname{Report}(\mathrm{e}, \mathrm{w}) \wedge A d-e e(e, w)=x \wedge\left[\forall w_{\text {suc }}\right. \text {. }
\end{aligned}
$$

The current analysis predicts that the embedded modal is obligatorily anchored to the matrix PRT-state, i.e. it cannot be interpreted as a modal with a circumstantial modal base anchored to the local event of the embedded proposition. This means that the embedded modal operator is higher than the embedded aspectual head, so that it cannot be bound to the local event (locality restriction in Hacquard 2006, 2010). Evidence from this comes from the fact that both variants in (14a), ADVISE+SUBJ and ADVISE+IND+MOD, are incompatible with a continuation which indicates that the advisor will prevent the fulfillment of the prejacent as in (14d) (unless the advisor is considered a liar). By contrast, with the verb leo 'say' there is a difference between SAY+SUBJ and SAY+IND+MOD. In the first case (14b), the continuation in (14d) is infelicitous. In the second case as in (14c), it is possible to have the continuation in $(14 \mathrm{~d})$ and it can be understood in a way that deontic necessity has to do with the 
circumstances, i.e. the advisee is a soldier and his commander has asked him to go back to the camp, but the advisor (i.e. his mom) does not endorse the commander's view and therefore trying to find ways prevent this from happening.
a. Ton simvulepsa $\{$ na figi $\} / \quad$ oti prepi na figi $\}. . \quad \#(14 d)$ him.CL advise.1SG SUBJ leave.3SG THAT must NA leave.3SG 'I advised him to leave/that he should leave \#but I'll do my best so that he doesn't leave.'
b. Tu ipa na figi... \#(14d) him.CL told.1SG SUBJ leave.3SG 'I told him to leave \#but I'll do my best so that he doesn't leave.'
c. Tu ipa oti prepi na figi... $\checkmark(14 \mathrm{~d})$ him.CL told.1SG THAT must NA leave.3SG
'I told him that he should leave... $\checkmark$ but I'll do my best so that he doesn't."
d. ala tha kano ta panda ja na mi figi. but FUT do.1SG everything for NA not leave.3SG but I'll do my best so that he doesn't leave.

Additional evidence for the anchoring of the modal to the matrix PRT-state comes from the fact that the prejacent always needs to refer to a time following the ADVISE-event. Although past tense on prepi 'should' is possible in (15a), it cannot be interpreted as referring to a time preceding the time of the ADVISE-event, i.e. the sentence is not possible in a context in which there was a party yesterday evening and my friend told me today that I should have gone to the party. It necessarily describes an advising event which preceded the time of the party. By contrast, (15b) is perfectly fine in a context where the party precedes the saying event.

a. Me simvulepse oti eprepe na pao sto parti. me.CL advise.PAST.3SG that ${ }_{\mathrm{IND}}$ must NA go.1sG to-the party 'He advised me that I should go to the party.' advising > party

b. $\mathrm{Mu}$ ipe oti eprepena pao sto parti. me.CL tell.PAST.3SG that ${ }_{\mathrm{IND}}$ must NA go.1SG to-the party 'He told me that I should go to the party.' advising $\lessgtr$ party

One question raised by the present analysis concerns the locality restrictions in event binding. ${ }^{7}$ Hacquard $(2006,2010)$, following Percus (2000), introduces a locality restriction according to which all world and event variables on the 'spine' of the tree $(T, A, M, V)$ need to be bound by the closest binder. As a reviewer notices,

$7 \mathrm{I}$ am grateful to a SALT-reviewer for raising this issue. 
the event of $\mathrm{C}_{\mathrm{IND}}$ operator is not bound by the closest binder, which is the PRT-event, but by the higher Report-event. Crucially, however, the closest PRT-event is not an appropriate binder for the event of IND because it has dual content (i.e. involves a doxastic and prioritizing content) which in order to be expressed requires an operator with a modal base and an ordering source (Portner \& Rubinstein 2020). IND only has a modal base, therefore the closest matching candidate is the Report-event. In this sense, this event is the closest matching event for $\mathrm{C}_{\mathrm{IND}}$. What is critical is that the matching candidate lies within the same domain, i.e. the domain of the embedding predicate. In this sense, the locality restriction is preserved, i.e. the event variable of IND must be locally bound, by an event which is below the matrix Asp-head. An operator cannot be relativized to an event outside the matrix TP.

\subsection{Illicit patterns}

Our analysis also predicts the ungrammaticality of ADVISE-PS+SUBJ+PRT-MODAL as shown in (16), repeated from (1d).

* Kapji simvulepsan ton Bernie na prepi na paretithi. some.PL advise.3PL the Bernie SUBJ should NA resign.3SG

'Some advised Bernie that he should resign.'

This restriction can be explained, since both operators contribute the same type of modality leading to a doubly prioritizing interpretation. The ungrammaticality of (1d) also suggests that no modal concord is possible between the higher SUBJ and the PRT-modal. Notice that a carefully constructed example in which there is a PRT-modal but is anchored to the circumstances of the embedded event is possible. In (17) prepi (translated as have to) is not relativized to the PRT-state. It has to do with the technical restrictions I implement on my computer, i.e. it works in a context in which a technician advises me how I can avoid deleting files by mistake. The circumstantial flavor of prepi in (17) is different from the flavor of the SUBJ.

(17) Me simvulepse na prepi panda na patao ke deftero kumbi ja na me.CL advised.3SG SUBJ must always NA press and second key for NA sviso ena arhio.

delete a file.

'He advised me that I should always have to press a second key as well, in order to delete a file.'

In addition, we predict that ADVISE-PS cannot combine with IND without a PRT-MODAL. Given the PRT-character of ADVICE we can understand why a modal with a dual background (a modal base and an ordering source) is necessary in order to express the prioritizing content (see Portner \& Rubinstein 2020). 
Modally conditioned mood-switch

In the same vein, we can understand why predicates like want or intend cannot combine with IND+PRT-MODAL. Since these predicates are monoeventive, the higher $\mathrm{C}_{\text {IND }}$ will not have a proper anchor for its modal base.

\section{Underspecified communication predicates}

Grano (2018); Giannakidou \& Mari (2021) discuss predicates of communication like TELL, PERSUADE, DECIDE, WARN which can combine with either SUBJ or IND (or non-finite/finite complements in English). The crucial difference between these predicates and ADVISE-Ps is that they do not obligatory encode a prioritirizing content. As such, they can combine with either SUBJ or IND, yielding a prioritizing (18a) and an informational (18b) reading accordingly (see Appendix).

a. Ton episa na erhete spiti i Ana. him.CL convinced.1SG SUBJ come.IMPRF.3SG home the.NOM Ana. 'I convinced him that Ana should come to our house.'

b. Ton episa oti erhete spiti i Ana. him.CL convinced.1SG $\mathrm{C}_{\text {IND }}$ come.IMPRF.3SG home the.NOM Ana. 'I convinced him that Ana is coming / comes to our house.'

Grano (2018) analyses PERSUADE-Ps as causative predicates which trigger a RATIONAL ATTITUDE. The ATTITUDE, can be either informational or prioritizing. Under Grano's (2018) view, communication predicates are underspecified. The preferential or informational modality is part of the semantics of to and that accordingly. However, Grano (2018) also assumes that the operators are relativized to the matrix attitude in order to explain distribution restrictions. Giannakidou \& Mari (2021) suggest that the difference between the two versions of PERSUADE is whether they have a nonveridical presupposition or not, i.e. (18a) is nonveridical while (18b) is not (Giannakidou \& Mari 2021: 178-179).

The current analysis shares with Grano 2018 the hypothesis that SUBJ and IND are modal operators. However, in the current framework the modal flavor of SUBJ and IND is not part of their semantics, instead it is acquired by relativizing to the matrix situation. In this sense, we would have to assume that communication verbs come into two varieties: one with a prioritizing flavor and the other with informational flavor, similar to the assumption in Giannakidou \& Mari (2021). Grano (2018) suggests the conjunction test to differentiate between the two hypotheses. If the predicate is underspecified, then we should be able to conjuct a finite and a nonfinite complement. If the predicate encodes a particular type of situation, then we should only be able to conjuct complements of the same type. In favor of the underspecification analysis he provides the sentences in (19): 
(19) a. I persuaded John [that the city is in danger and PRO to evacuate immediately].

b. I persuaded John [PRO to evacuate immediately and that the safest place to be is by the sea.]

One consideration with (19b) is that it already has a modal component (the safest place to be = the safest place one should be). In Greek there seems to exist a contrast depending on the type of the sentences that are conjoined. Crucially for the current analysis, there is a contrast between (20b), which conjoins a SUBJ and an IND without a modal and (20c), which conjoins a SUBJ and an IND+MODAL:

a. $\checkmark$ Ton episa oti prepi na episkefti enan giatro ke oti him.CL persuaded.1SG $\mathrm{C}_{\text {IND }}$ must NA visit.3SG a doctor and $\mathrm{C}_{\mathrm{IND}}$ ta simpliromata diatrofis ine epikindina. the supplements nutrition.GEN are dangerous. 'I persuaded him that he must visit a doctor and that the food supplements are dangerous.'

b. ?\% Ton episa na episkefti enan giatro ke oti ta him.CL persuaded.1SG SUBJ visit.3SG a doctor and $\mathrm{C}_{\mathrm{IND}}$ the simpliromata diatrofis ine epikindina. supplements nutrition.GEN are dangerous

'I persuaded him to visit a doctor and that the food supplements are dangerous.'

c. ?Ton episa na episkefti enan giatro ke oti prepi na him.CL persuaded.1SG SUBJ visit.3SG a doctor and $\mathrm{C}_{\text {IND }}$ must NA stamatisi ta simpliromata diatrofis.

stop the supplements nutrition.GEN.

'I persuaded him to visit a doctor and that he must stop getting nutrition supplements.'

However, the contrasts are subtle and there seems to be variability among speakers. This type of contrasts needs to be further investigated in experimental work. For now we will stick to the current view under which some attitude information needs to be specified in the embedding predicate.

\section{Mood as modal: Further implications and issues}

Treating MOOD as a modal also provides an apparent solution for the interpretation of SUBJ-marked utterances in other environments. As noticed in Section 2, matrix subjunctives in Greek have a prioritizing interpretation without any overt modal 
operator (Giannakidou 2015; Oikonomou 2016; Stegovec 2019 a.o.). For these cases, it is reasonable to assume that SUBJ encompasses the prioritizing semantics. Similarly, SUBJ-questions in Greek have a prioritizing interpretation (see Oikonomou 2016; Giannakidou \& Mari 2021).

(21) $\mathrm{Ti}$ na fai $\mathrm{i}$ Maria?

what SUBJ eat.3SG the.NOM Maria.

'What should Maria eat?'

Another case of mood-switch is attested with verbs typically combining with IND alternating with SUBJ. For example, believe in Greek typically combines with IND but it can also combine with SUBJ. Giannakidou (2015) notes that, when believe combines with SUBJ, its meaning shifts to encoding hope. Under a semantic approach to mood, this meaning-shift can be analysed as a type of coercion (Safir 2020).

Despite its advantages, the current analysis still faces familiar challenges for intra- and cross-linguistic variability (see the discussion in Portner \& Rubinstein 2020). In addition, assigning a (human) necessity interpretation to SUBJ does not always comply with our intuitions. Most obviously, SUBJ-complements combine with predicates offering permission:

(22) O Nikos epetrepse na kimithi i Maria sto spiti. the Nick allowed SUBJ sleep.3sg the.NOM Maria at-the house.

'Nick allowed for Mary to sleep at the house.'

In addition, matrix subjunctives in Greek can convey permission (Oikonomou 2016):

a. Entaksi, na pas sto parti.

OK, SUBJ go.2sg to-the party.

'Ok, go to the party.' $\rightsquigarrow$ You can go to the party.

b. Na pai i Maria sto parti?.

SUBJ go.3sg the.NOM Maria to-the party

'Can Maria go to the party?' $\rightsquigarrow$ Do you allow her to go to the party?

A consideration of these issues should take into account the crosslinguistic differences in the force of subjunctives (i.e. in Serbian the force in matrix subjunctives seems to be human necessity as discussed in Kaufmann, Todorović \& Jovović 2021; Oikonomou \& Ilić 2021). The phenomenon of mood-switch with Advise-Ps appears in other languages too (e.g. Bulgarian, Romanian, Spanish, French), suggesting that we can find additional cross-linguistic evidence for a mood-as-modal approach. 


\begin{tabular}{|l|l|l|}
\hline Communication PRT-Ps & Non-communication PRT-Ps & Communication Ps \\
\hline simvulevo 'advise' & thelo 'want' & leo 'say' \\
\hline protino 'suggest' & efhome 'wish' & eksigo 'explain' \\
\hline parotrino 'urge' & skopevo 'intend' & rotao 'ask' \\
\hline parakalao 'request' & protimao 'prefer' & grafo 'write' \\
\hline daskalevo 'teach/advise' & epithimo 'desire' & pitho 'convince' \\
\hline
\end{tabular}

\section{Table 1 Verbs per predicate-type}

\section{A Experimental survey: Preliminary results}

In this Appendix, I present preliminary results from an online study which investigates the possibility of mood-switch with three different classes of predicates, communication PRT-Ps, non-communication PRT-Ps, and communication-Ps with underspecified attitude (i.e. consistent with informational or prioritizing content).

\section{A.1 Design \& materials}

We used a Sentence Evaluation Task with a continuous slider. Each trial presented an initial context and then four sentences which represented the following four conditions (presented in random order):
a. $\mathrm{V}+\operatorname{SUBJ}($ i.e. 1a)
b. $V+$ IND + MOD (i.e. $1 b)$
c. $\mathrm{V}+\mathrm{IND}$ without MOD (i.e. 1c)
d. $\quad$ V + SUBJ + MOD (i.e. 1d)

There were three different types of predicates: i) communication PRT-Ps, ii) noncommunication PRT-Ps and iii) communication underspecified Ps. We tested each type of predicate with five different verbs listed in Table 1.

Thus we had in total 15 trials (and 15 fillers), in each of which the participants had to evaluate four sentences which differed minimally in their embedding strategy as presented in (24). The participants had to rate each of the four sentences on a continuous slider from 0 (=entirely unnatural) to 100 (=entirely natural). The study is implemented in Gorilla Experiment Builder (www.gorilla.sc) (Anwyl-Irvine, Massonnié, Flitton, Kirkham \& Evershed 2018). The results presented below are from 40 participants recruited via Prolific (the study is ongoing with our target being 60 monolingual participants). 


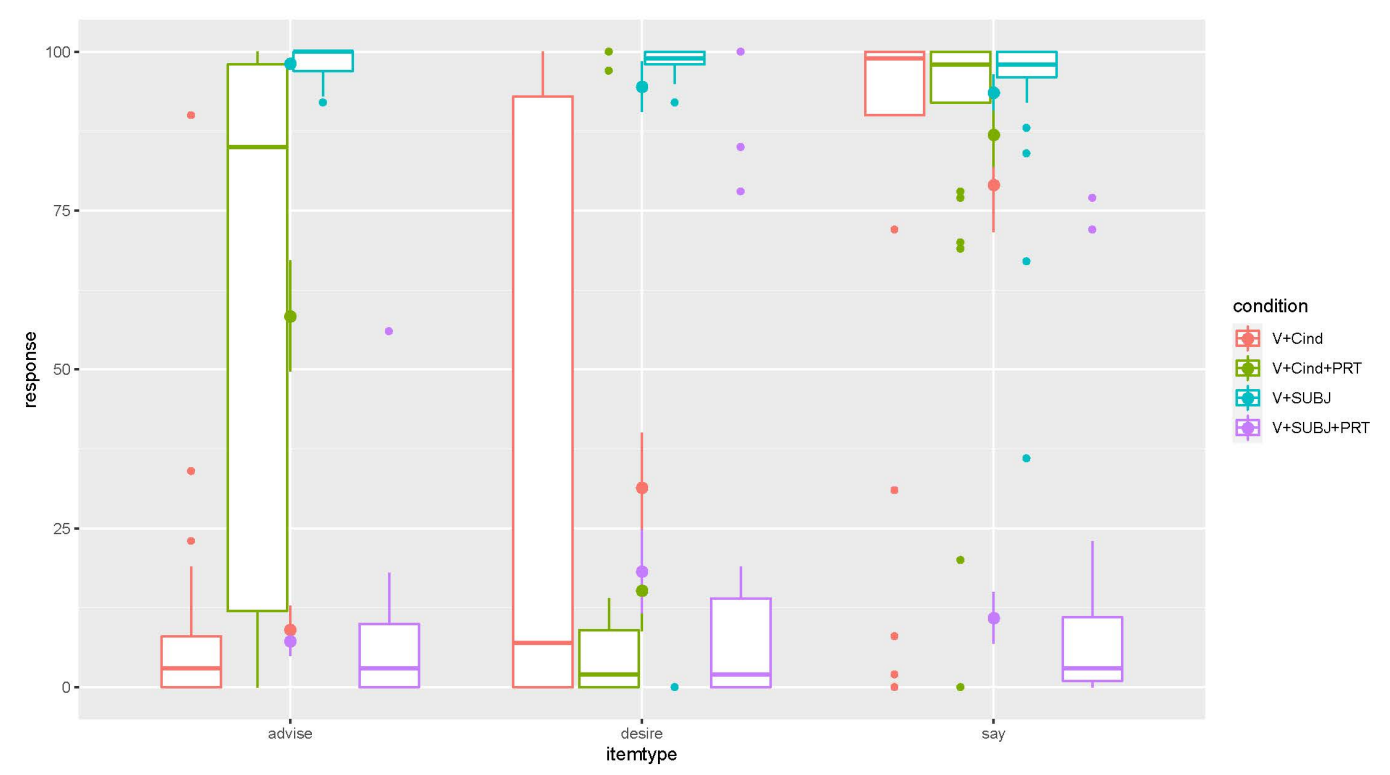

Figure 1 The evaluation of the sentences is shown on the y axis on a scale from 0 (unnatural) to 100 (entirely natural).

\section{A.2 Results \& discussion}

Figure 1 presents the preliminary results from 40 monolingual speakers. The bold lines in the boxplot represent the median while the dots represent the mean response for each item type. The boxplots also show the distribution of the responses in quartiles and outliers are represented by individual dots. The mean dots reflect variation with error bars showing one standard deviation. ${ }^{8}$ As we can see, the results support the original observation V + IND + MOD is acceptable with communication PRT-Ps but not with non-communication PRT-Ps. The default V+SUBJ is at ceiling across all predicate-types. Communication underspecified Ps are evaluated high in all conditions except the V+SUBJ+MOD. The critical condition is the V+IND+MOD, the mean for communication PRT-Ps (ADVISE-PS) is $58.4 \%$ whereas for noncommunication PRT-Ps (DESIRE-PS) the mean is $15.2 \%$. As shown in Figure 1, there is large variability in responses in V+IND+MOD. This is partly due to item variation (i.e. while for simvulevo 'advise' mean evaluation is $80 \%$, for parakalao it is $35 \%$. This variability needs to be further explored in order to identify the types of predicates and contexts which favor this type of mood-switch.

8 I am extremely grateful to Dan Bondarenko and Onur Özsoy for the plotting and discussion of the data. 
Oikonomou

\section{References}

Anwyl-Irvine, Alexander, Jessica Massonnié, Adam Flitton, Natasha Kirkham \& Jo Evershed. 2018. Gorillas in our midst: Gorilla.sc, a new web-based experiment builder. bioRxiv doi:10.1101/438242. https://www.biorxiv.org/content/early/ 2018/10/22/438242.

Bhatt, Rajesh. 2008. Covert modality in non-finite contexts. De Gruyter Mouton.

Bondarenko, Tanya. 2020. Two paths to explain. Handout at BCGL13, December 16-18, 2020.

Condoravdi, Cleo \& Sven Lauer. 2012. Imperatives: Meaning and illocutionary force. In Empirical Issues in Syntax and Semantics 9, 37-58.

Demirok, Ömer, Denız Özyıldız \& Balkız Öztürk. 2019. Complementizers with attitude. In Maggie Baird \& Jonathan Pesetsky (eds.), 49 Annual Meeting of the North East Linguistic Society (NELS 49), vol. 3, 213-222. Amherst, MA: GLSA Publi- cations.

Dobrovie-Sorin, Carmen. 2001. Head-to-head merge in balkan subjunctives and locality. Comparative Syntax of Balkan Languages 44-73.

Driemel, Imke \& Maria Kouneli. 2020. "say"-based complementation: Insights from kipsigis. Handout at BCGL13, December 16-18, 2020 .

Elliott, Patrick D. 2020. Elements of clausal embedding: UCL (University College London) PhD dissertation.

Farkas, Donka. 1992. On the semantics of subjunctive complements. Romance Languages and Modern Linguistic theory 69-104. doi:https://doi.org/10.1075/cilt.91.07far.

Farkas, Donka. 2003. Assertion, belief and mood choice. In Paper presented at the Workshop on Conditional and Unconditional Modality, Vienna.

Giannakidou, Anastasia. 1998. Polarity sensitivity as (non) veridical dependency. John Benjamins, Amsterdam-Philadelphia. doi:https://doi.org/10.1075/la.23.

Giannakidou, Anastasia. 2015. Evaluative subjunctive as nonveridicality. In Tense, mood, and modality: New answers to old questions, ed. by Blaszack J. et al., .

Giannakidou, Anastasia \& Alda Mari. 2021. Truth and Veridicality in Grammar and Thought. University of Chicago Press. doi:https://doi.org/10.7208/9780226763484.

Giorgi, Alessandra \& Fabio Pianesi. 1997. Tense and aspect: From semantics to morphosyntax. Oxford University Press, USA. doi:10.2307/417406.

Grano, Thomas. 2018. Belief, intention, and the grammar of persuasion. In Chicago Linguistic Society 54 (CLS 54), 125-135.

Hackl, Martin \& Jon Nissenbaum. 2012. A modal ambiguity in forinfinitival relative clauses. Natural Language Semantics 20(1). 59-81. doi:https://doi.org/10.1007/s11050-011-9075-9. 
Modally conditioned mood-switch

Hacquard, Valentine. 2006. Aspects of modality. Cambridge, MA: Massachusetts Institute of Technology (MIT) $\mathrm{PhD}$ dissertation.

Hacquard, Valentine. 2010. On the event relativity of modal auxiliaries. Natural Language Semantics 18(1). 79-114.

Kaufmann, Magdalena. 2012. Interpreting Imperatives. Berlin: Springer. doi:10.1007/978-94-007-2269-9.

Kaufmann, Magdalena. 2016. Fine-tuning natural language imperatives. Journal of Logic and Computation 29(3). 321-348. doi:10.1093/logcom/exw009. https: //doi.org/10.1093/logcom/exw009.

Kaufmann, Magdalena, Neda Todorović \& Ivana Jovović. 2021. Obviate me (not): Obviation effects in Serbian main and complement clauses. Handout from FASL31 at MIT .

Koenig, Jean-Pierre \& Anthony R Davis. 2001. Sublexical modality and the structure of lexical semantic representations. Linguistics and Philosophy 24(1). 71-124. doi:https://doi.org/10.1023/A:1005616002948.

Kratzer, Angelika. 2006. Decomposing attitude verbs. Talk at the Hebrew University of Jerusalem honoring Anita Mittwoch on her 80th birthday .

Kratzer, Angelika. 2016. Evidential moods in attitude and speech reports. In Talk at UConn Colloquium, September $9^{\text {th }}$, Universityof Connecticut .

Mari, Alda \& Paul Portner. 2018. Mood variation with belief predicates: Modal comparison in semantics and the common ground. Manuscript, ENS and Georgetown University .

Martin, Fabienne \& Florian Schäfer. 2013. On the argument structure of verbs with bi-and mono-eventive uses. In Annual Meeting of the North East Linguistic Society (NELS 42), 297-308. Amherst, MA: GLSA Publi- cations.

Moulton, Keir. 2009a. Clausal complementation and the wager-class. In A. Schardl \& M. Walkow (eds.), Annual Meeting of the North East Linguistic Society (NELS 38), 165-178. Amherst, MA: GLSA Publi- cations.

Moulton, Keir. 2009b. Natural Selection and the Syntax of Clausal Complementation. Amherst: Umass PhD dissertation.

Oikonomou, Despina. 2016. Covert modality in root contexts. Cambridge, MA: Massachusetts Institute of Technology (MIT) PhD dissertation.

Oikonomou, Despina \& Ivona Ilić. 2021. Subjunctive questions in serbian. Handout from FASL31 at MIT .

Percus, Orin. 2000. Constraints on some other variables in syntax. Natural Language Semantics 8(3). 173-229. doi:https://doi.org/10.1023/A:1011298526791.

Portner, Paul. 1997. The semantics of mood, complementation, and conversational force. Natural Language Semantics 5(2). 167-212. doi:https://doi.org/10.1023/A:1008280630142.

Portner, Paul. 2018. Mood. Oxford University Press. 
Portner, Paul \& Aynat Rubinstein. 2012. Mood and contextual commitment. In Semantics and Linguistic Theory, vol. 22, 461-487.

Portner, Paul \& Aynat Rubinstein. 2020. Desire, belief, and semantic composition: Variation in mood selection with desire predicates. Natural Language Semantics 28. 343-393. doi:https://doi.org/10.1007/s11050-020-09167-7.

Quer, Josep. 2001. Interpreting mood. Probus 13(1). 81-111. doi:https://doi.org/10.1515/prbs.13.1.81.

Quer, Josep. 2009. Twists of mood: The distribution and interpretation of indicative and subjunctive. Lingua 119(12). 1779-1787.

Roussou, Anna. 2010. Selecting complementizers. Lingua 120(3). 582-603. doi:https://doi.org/10.1016/j.lingua.2008.08.006.

Safir, Ken. 2020. The directions of selection. Handout at BCGL13, December 16-18, 2020 .

Schlenker, Philippe. 2005. The lazy frenchman's approach to the subjunctive. Romance Languages and Linguistic Theory 269-309.

Schwager, Magdalena. 2006. Interpreting imperatives. Frankfurt: University of Frankfurt/Main $\mathrm{PhD}$ dissertation.

Silk, Alex. 2018. Commitment and states of mind with mood and modality. Natural Language Semantics doi:10.1007/s11050-018-9144-4.

Stegovec, Adrian. 2019. Perspectival control and obviation in directive clauses. Natural Language Semantics 27(1). 47-94. doi:10.1007/s11050-019-09150-x.

Villalta, Elisabeth. 2008. Mood and gradability: an investigation of the subjunctive mood in spanish. Linguistics and Philosophy 31(4). 467-522. doi:https://doi.org/10.1007/s10988-008-9046-X.

Despina Oikonomou

Unter den Linden 6, 10099

despina.oikonomou@hu-berlin.de 